\title{
Measuring destination image of an Italian island: An analysis of online content generated by local operators and tourists
}

\author{
Valentina Marchi \\ Institute of BioEconomy, National Research Council, Florence, Italy \\ valentina.marchi@ibe.cnr.it (corresponding author)
}

\author{
Antonio Raschi \\ Institute of BioEconomy, National Research Council, Florence, Italy \\ antonio.raschi@ibe.cnr.it
}

\begin{abstract}
The understanding of destination image is a key point for tourism enterprises, local authorities, and policy makers. This study explores the case of Capraia, a small island located in Tuscany, to analyze how tourists (tourism demand) and local operators (tourism supply) create and communicate the island's online image. This research quantitatively examines online communication on the two sides of the tourism market to monitor the online destination image of the island of Capraia. To build on previous research in this area, this study adopts a web content mining approach to assess the characteristics of content published online. The main dimensions of destination image (as developed in the literature) are used as a basis to create a dictionary for automated content analysis. A total of 24 tourism promotion websites and 9,180 tourist Instagram posts were analyzed. Findings reveal discrepancies between the image proposed by local operators and that perceived by tourists. Local operators mostly communicate general information to discover the destination, while tourists prioritize communication based on emotional appeal and personal experience on the island. This research aims to provide support for local operators and policy makers in decisions relating to communication and in defining the island image.
\end{abstract}

Keywords: Capraia island, content analysis, destination image, destination marketing, text mining, tourist consumer behaviour.

https://doi.org/10.24043/isj.168 • Received February 2021, accepted July 2021

(C) Island Studies Journal, 2021

\section{Introduction}

Destination image has been a very common object of study in tourism research since its recognition as a factor in tourism development (Hunt, 1975). As a key element to differentiate a destination, understanding its formation is crucial for both professionals and scholars (Kislali 
et al., 2016). Accordingly, a vast body of literature has been developed with the aim of conceptualizing destination image, its dimensions, its measurement, and its influences.

Traditionally, destination image has been created and generated by Destination Marketing Organizations (DMOs) with the purpose of differentiating a destination, and then disseminated mainly through printed materials to potential customers, resulting in a one-way conversation with the consumer (Blain et al., 2005; Lim et al., 2012). The emergence of the Internet has altered these communication patterns; in particular, social media has become a powerful source of "word of mouth" communication, influencing tourists' choices and becoming a valuable source of travel information. On the other hand, the use of social media by DMOs and tourism operators has made two-way conversation possible in the construction of a destination image (Lim et al., 2012). Very quickly, tourism has become an informationintensive sector that relies on the Internet to distribute its products and to communicate with customers (Kim S. E. et al., 2017). This technological change and its impact on tourist choice have brought new questions in this research field, as well as new tools for understanding destination branding. Websites and social network platforms have become a mine of data that sector practitioners can use for testing existent models and developing new ones.

Empirical and theoretical studies have outlined the important role that local operators, DMOs, and policy makers play in building the destination image (Choi et al., 2007; Kong et al., 2015). However, there is limited research on the comparison between the communication of local operators/DMOs/institutions (tourist supply) and tourists (tourist demand). Previous studies have focused on online photographs generated by tourists and government agencies (Michaelidou et al., 2013; Stepchenkova \& Zhan, 2013; Zhang et al., 2019) or, in a few cases, to the combination of textual and photographic data (Mak, 2017). Additionally, several studies have deeply investigated geotagged photos published by tourists as compared with the distribution of the attractions promoted by DMOs (Nechita et al., 2019). To advance previous research, the current study adopts a content mining approach based on textual content generated online by both the demand and supply sides. The destination image, both perceived and projected, is analyzed following the theoretical framework identified in the literature, which is based on dimensions recognized as factors influencing destination image.

This study aims to contribute in advancing the understanding of online communicated destination image, in turn supporting policy makers in adopting targeted strategies to enhance tourism on remote islands. The study uses text mining techniques to analyze the online communication of an Italian destination: the island of Capraia. Analyzing online content published by local operators on their websites and by tourists on the social networking platform Instagram, our research focuses on how destination image is communicated by local operators and tourists, and examines differences between their published content to determine whether tourism communication reflects the image perceived by tourists.

\section{Research background}

The tourism journey represents a break from the everyday life, and it begins when future tourists develop an interest for a destination. Before the booking process, tourists go through a preliminary phase of inspiration in which they search for information, dream about their future experiences, and build expectations (Kim J. \& Fesenmaier, 2017). Tourists' motivation is driven by their belief(s) about a destination. As such, understanding how the tourism offer 
is designed and promoted plays an important role for operators and institutions; communication and perception of destination image influence tourist behavior and destination success (Tasci \& Gartner, 2007).

The concept of destination image was originally developed to analyze the psychological forces that motivate the traveler and influence destination choice. Researchers have provided several definitions of 'destination image' and different techniques for measuring it. Among the definitions provided over the decades, Crompton $(1979$, p. 18) stated that "an image may be defined as the sum of beliefs, ideas, and impressions that a person has of a destination." Furthermore, Dichter (1985, p. 75) underlined that destination image "describes not individual traits or qualities, but the total impression an entity makes on the minds of others." An element that all definitions have in common is that destination image is a set of impressions and feelings obtained from various channels; consequently, the result achieved leads to a mental construction of destination image (Li et al., 2015). Different components are considered for destination image construction, such as cognitive (beliefs and knowledge on the physical attributes of destination), affective (emotions and feelings that a place evokes in tourists), and conative (behavioral intentions, influenced by cognitive and affective components) (Baloglu \& McCleary, 1999; Gartner, 1994). Owing that the affective and the conative images mainly depend on the perception of the cognitive component (Lee S. W. \& Xue, 2020), empirical studies have typically placed more attention on the latter.

Beerli and Martin (2004) identified the attributes for measuring destination image in relation to cognitive components and classified them into nine dimensions: natural resources; general infrastructure; tourist infrastructure; tourists leisure and recreation; culture, history, and art; political and economic factors; natural environment; social environment; and atmosphere of the place. Each dimension incorporates attractions and attributes that influence image assessment. The attributes were selected through a review of existing studies with the aim of creating a universally accepted scale to measure destination image. The attribute(s) chosen depends on the attractions available in the place analyzed, which will also determine the selection of specific or more general attributes. Li et al. (2015) recently carried out an exhaustive review of the literature dealing with the role of destination image measurement, focusing on the cognitive components and on these nine dimensions. Overall, they found that the most commonly analyzed components are related to natural environment and tourism infrastructure, while the least common dealt with general infrastructure and atmosphere of the place.

Destination image is traditionally created and designed by DMOs, in their role as organizations responsible for destination marketing and management of tourist destinations. However, despite the great efforts made by DMOs to create, promote, and communicate destination image, it is not always correctly perceived by tourists. Destinations work intensively on defining a persuasive destination image, adopting branding strategies with the aim of differentiating the identity of a territory and thereby making it more competitive (Blain et al., 2005). The concept of destination branding was developed at the end of the 1990s and its academic interest has grown significantly in the last decade. It is widely emphasized that a destination branding concept is not only a name or a logo, but is composed of various aspects which must be incorporated into the branding, such as visitors' experience (Kavaratzis \& Hatch, 2013). In a recent study, Ruiz-Real and colleagues (2020) highlighted the importance of strategy planning on medium- and long-term destination branding, focusing on authentic and experiential tourism offerings. This would enable destination differentiation and allow 
high customer-based brand equity through the involvement of travelers in the creation of branding (Ruiz-Real et al., 2020). Following the concept defined by Oliveira and Panyik (2015, p. 53), "the most successful destinations will be those that abandon the traditional topdown approach in favor of bottom-up and co-created branding strategies." Issues with the creation of top-down place branding are addressed in Grydehøj's (2008) study on the Shetland Islands, where a new official brand conflicted with local perceptions and experience due to the development of a poor identity concept.

In order to plan the destination branding strategy and evaluate communication effectiveness, DMOs should consider how different subjects perceive the destination and translate their experience in content that contributes to defining its image. In the last decade, different subjects have contributed in the creation of destination image through a variety of online channels such as social networks, websites, and blogs. Increasingly, online content has been a mine of information for people during the travel research process (Xiang et al., 2009), as users share holiday experiences on social media, creating user-generated content (UGC).

UGC represents a source to trace the experience and emotion of a tourism destination, and more and more researchers are investigating and testing destination image through the analysis of data extracted from websites or social networks (Költringer \& Dickinger, 2015). The two main approaches for quantitative measurement of destination image are based alternatively on structured data (i.e., surveys) or on unstructured data (i.e., in-depth interview, content analysis). The survey method has long been applied by researchers and has been adopted with the aim of analyzing destination image constructions in different countries (Alcañiz et al., 2009), while online content analysis is a more recent approach and is related to the continuous evolution of the Internet. In the unstructured data field, web content and social media have made a vast amount of data available in different formats, such as text, videos, and photos. One example of such an approach is that of Choi et al. (2007), who performed content analysis with the purpose of extracting elements from unstructured data to measure destination image in Macau.

Due to the large amount of data available in text format, as highlighted by Guo and colleagues (2016), it has become necessary to move from what is called manual content analysis to a computer-assisted text analysis methodology. Computer-assisted methodologies can be identified as dictionary-based text analysis or unsupervised machine learning algorithms. In the first case, researchers identify keyword lists for each topic of interest; these lists are defined as a 'dictionary'. For each analysis unit, the computer scans to see if selected keywords are present. These methodologies require a preliminary selection of interest elements and keywords by researchers. In addition to identifying specific topics, this approach is used in the literature to perform sentiment analysis (Taboada et al., 2011). Meanwhile, the unsupervised machine learning algorithms are statistical-computational techniques. Starting from unstructured and untagged data, their aim is to identify patterns that allow users to understand the structure. Within the broader framework of content analysis, topic models have been developed. Among these, the most widely used is Latent Dirichlet allocation (LDA; Blei et al., 2003).

Destination image can be analyzed with different methodologies, following two main perspectives: the projected image, communicated by DMOs and the tourism industry, and the image perceived by tourists (Kim S. \& Lehto, 2013). Designing a distinctive destination brand can influence tourist perceptions as well as post-purchase evaluations (Kim S. \& Lehto, 2013). 
At the same time, the perceived value is a factor that can determine tourist behavior by increasing the intentions of return and the desire to visit the place again (RamseookMunhurrun \& Naidoo, 2015).

Based on this premise, how is the destination image communicated by tourism market (both supply and demand)? The remote Italian island of Capraia, which is one the seven islands of the Tuscan Archipelago, was identified as the focus of the current study. In recent years, policy makers and stakeholders on Capraia have been working intensively on tourism strategic planning, focusing on an authentic and experiential tourism offer which differentiates their island from other destinations. The DMO, municipality, and local operators are jointly cooperating in the identification of medium- and long-term actions plans to be developed (until 2030). To achieve this purpose, the island branding should be designed by also incorporating visitors' points of view.

\section{The case study of Capraia}

The choice of Capraia as the test site for this study is related to its characteristics as a small island $\left(19 \mathrm{~km}^{2}\right)$ that is readily identifiable as a tourist destination. Capraia is easier to set apart from other destinations due to its administrative boundaries and its natural physical boundaries given by the surrounding sea (Fedele et al., 2011).

Capraia boasts well-defined historical, cultural, and natural attractions. Its history has been documented since the Roman times, when it became the refuge of hermits. Throughout the Middle Ages, Capraia was involved in the wars between Pisa and Genoa, and was often occupied by Saracen pirates; eventually, Genoa established military control of the island, still evidenced by the presence of fortresses and towers that made the island an efficient outpost for the control of the Tyrrhenian Sea. In the 19th century, Capraia belonged to the Kingdom of Sardinia, and then to the Italian State, which established a convict penal colony on the island in 1873.

Capraia is hilly, culminating in Monte Castello, which is 443 meters high. Stagnone, a little lake on the hills, often houses a population of migratory birds and, in the past, was a precious water source in dry Mediterranean summers. Capraia is of volcanic origin, made by the overlapping of two volcanoes, and the main visible character is in the southern part of the island in the Cala Rossa, a cove that is part of an ancient crater. This is one of the most famous points of the island thanks to its red rocks that join the blue of the crystalline sea.

The landscape of Capraia was deeply influenced by the establishment of the penal agricultural colony in 1873, which limited the possibility to build new houses, and public access was restricted until the constitution of the Arcipelago Toscano National Park in 1996 (Camilleri et al., 2012). The rural penal colony was located in the north of the island and operated until its closure in 1986. All of the structures were abandoned and it was only in 2008 that the Italian Supreme Court decreed that the management of the property be conferred to the municipality and that the establishments could be allocated for civil use. Following this decree, some parts of the old penal colony have been taken over by citizens with the aim of enhancing territory, landscape, and products. As a result, production of highquality wine, cheeses, honey, and vegetables is now present on the island.

The territory of the whole island, apart from the agricultural cultivations, is covered by Mediterranean forest. Capraia has been studied by several authors for its geographic location 
and climate, with research mainly focusing on the geology and endemic flora and fauna of the island (see, e.g., Foggi et al., 2015; Santo, 2021). It is interesting to note that Capraia is the northernmost location in the world where a wild population of palms can be observed.

The coast of the island is rocky and difficult to access, featuring many coves (cala) and caves (grotte). Due to its morphologic characteristics, the island is mainly accessible by foot or by boat, as there are only 800 meters of paved road. Thanks to the will of local stakeholders, many trekking routes have been developed to reach the coves and discover the island's many panoramic points. Every summer, the Park Authority and the Municipality promote these trekking paths by offering free daily tours with a professional guide.

Tourism in Mediterranean destinations is characterized by a strong seasonality. The highest occupancy rate on Capraia is recorded in the peak season, from June to September, with large differences in occupancy rates between winter and summer. During the winter months, most hotels on the island are closed. According to the official data of the Tuscany Region statistical office (Regione Toscana, 2018), the average length of tourists' stays in 2017 was 3.3 days. The total number of overnight stays in commercial and noncommercial accommodation was 20,436 for the year, and the number of tourist arrivals was 6,239 . In 2017, $93.3 \%$ of tourist arrivals and $91.5 \%$ of overnight stays were related to Italian nationals (domestic tourism) (Regione Toscana, 2018). Due to the difficulties of reaching the island (approximately 3 hours each way, with a maximum of two daily crossings), it is rare to for tourists to make day trips to the island. One of Capraia's main strategic goals as a destination is to engage tourists and attract them during the low season. Cultural and gastronomic events are mainly organized to facilitate tourism to this end. The most popular event on Capraia is the Sagra del totano ('Squid festival') at the end of October, attracting a high number of tourists on a low season weekend.

\section{Methodology}

\section{Research design}

In order to understand how destination image is communicated, text mining techniques were used to examine online content, following an approach based on the framework developed by Beerli and Martin (2004).

Based on the premise that the involvement of various stakeholders can contribute to designing a more competitive destination image (Kong et al., 2015), this study was designed considering a range of subjects, and included the analysis of online content generated by:

i) tourism operators and institutions (labelled as supply-generated content; SGC) on websites to promote destination services and attractiveness; and

ii) tourists (labelled as demand-generated content; DGC) on Instagram to share personal experiences and feelings about a destination.

This distinction is consistent with the composition of the local tourism market and is functional in measuring whether the destination image proposed by operators matches consumers' beliefs and experiences.

In order to define the prevalent dimensions communicated online by both the supply and demand sides, our study was constructed as follows. In the first stage, the methodological approach has been mainly based on content analysis, which is founded on the idea that "many 
words of a text can be classified into much fewer content categories" (Weber, 1990, p. 7). Many previous studies on destination image used structured data based on methods such as surveys (Alcaniz et al., 2009; Kim S. S. et al., 2009; Qu et al., 2011). With the growth of tourism-related online content, increasingly also being generated by tourists, these data have been used in the literature to test existing models and to develop new ones. Studies on destination image have proved the reliability of unstructured data in comparison with traditional methods (Stepchenkova et al., 2009). Based on this, the current study uses unstructured textual data to measure destination image. Following this framework, the study suggests a dictionary-based approach in which dictionaries are developed and tested to detect the destination image of Capraia. In comparison to machine learning methods (e.g., SVM, Naive Bayes, k-NN), Schmunk and colleagues (2013), analyzing online tourist reviews, showed that the dictionary-based approach achieves good and satisfactory accuracy in the classification of product properties.

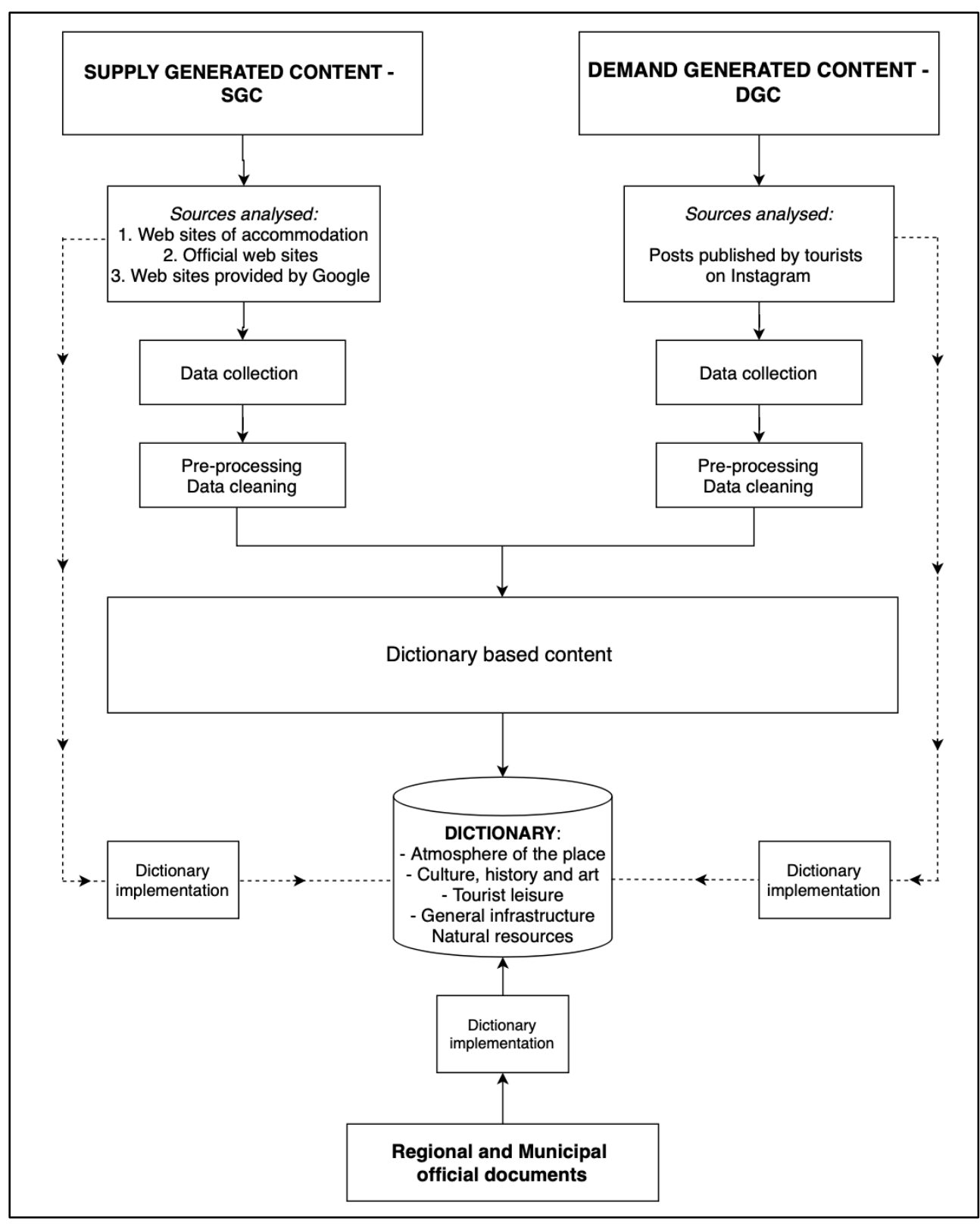

Figure 1. Research process. 
Data collection and data analysis

Data collection was conducted through the extraction of online generated content written in Italian. The decision to use Italian-language content was made in order to allow for a more homogeneous sample (both in terms of supply and demand), as Italians represent more than 90\% of the tourists on Capraia. Different sources were identified to analyze the two sides of the tourism markets. Figure 1 shows the process implemented to carry out the research.

On the side of content generated by operators and institutions (supply; SGC), data were extracted in May 2017 from three sources identified as:

(i) Websites of accommodation facilities on the destination (in order to focus exclusively on destination contents, texts were retrieved from website sections dedicated to Capraia and not to hotel services);

(ii) Official websites on Capraia promoting services to discover the island, such as municipality or boat excursion websites; and

(iii) Web pages provided by Google search engine through specific queries identified (i.e., Isola di Capraia). For example, the study considered web pages from blogs that talk about the island. Supported by the literature (Xiang \& Gretzel, 2010), Google was selected because it is current online search technology and is one of the main websites generating and directing the most traffic to specific websites in relation to the tourism sector.

On the Internet, a lot of tourism content is generated on specific platforms, such as TripAdvisor and Airbnb, which are review sites. For this reason, their content is not included in this sample. The total sample is composed of 24 websites analyzed, of which $29.2 \%$ included accommodation facilities located on the island (Capraia counts 7 accommodation facilities with a total of 478 beds), $33.3 \%$ are related to the official websites on the island, and $37.5 \%$ are websites provided by Google.

On the demand side (DGC), the study analyzed a pool of UGC on Instagram to detect communication and perception of Capraia as a tourist destination. The choice of Instagram as a source of content posted by tourists is related to its increase in popularity, confirmed by statistics: Instagram reached one billion monthly active users in June 2018, as compared to its 800 million in September 2017 (Statista, 2021). Through a preliminary screening, data retrieved consisted of 9,180 Instagram posts. This study included posts published over a fouryear time period, from January 2013 to July 2017, with the aim of analyzing different types of tourists and considering the seasonality that characterizes the island's tourism sector. Furthermore, the long time span was included to capture different communication nuances in relation to the platform's increasing popularity over this time period. We selected posts labelled by users with the following specific hashtags: \#capraia, \#isolacapraia, \#capraiaisland, and \#capraiaisola. A preliminary analysis of the total sample provided a fragmented framework of results. The high incidence of posts published by Capraia residents promoting the island led to the need to identify and select photos posted only by tourists in order to analyze the destination in a purely touristic aspect. As a result, the sample was filtered based on the user's presence in the destination over time. Based on the method used by Girardin and colleagues (2008), posts were filtered using a 7-day time span between the first and the last date of posting, categorizing 'tourists' as those that posted their content within a 7-day period, and 
assuming all others to be residents or tourism operators. The final sample on which the analysis was performed was 4,928 posts.

Data collected from both the demand and supply sides were anonymized and a preprocessing operation was carried out with the aim of deleting punctuation marks, stop words, and duplicate results. Our research adopted statistical-computational techniques to analyze SGC and DGC, which was performed using R software (Welbers et al., 2017). For the purpose of the study, dictionaries were built to detect the communication of the destination image of Capraia. In line with previous studies (Beerli \& Martin, 2004; Li et al., 2015), researchers included the five significant dimensions recognized as categories to deepen destination image: natural resources; tourist recreation; atmosphere of the place; culture, history, and art; and general infrastructure.

Dictionaries consist of word lists, without term overlaps between the dimensions, composed by unigram, bigram, and trigram. The relevant keywords included in the dictionaries used in this study are the results of an automated text analysis of the following resources: regional and municipal official documents (i.e., Valorization Plan, Strategic documents, etc.), website content, and Instagram posts. The occurrences of keywords in each textual file collected were counted. Finally, each text was represented in terms of frequencies of words in the dictionaries. The number of frequencies in each text was divided by the total number of words in each text to avoid longer texts being over-represented.

The validation method of the dictionary considered frequency counts (how often certain concepts occur in the texts) and Keyword in Context (KWIC) Indexing. KWIC is performed on DGC and SGC with the aim of contextualizing words in the text and identifying the meaning attributed to them by operators and tourists. KWIC indexing system is automatic and enables users to search a particular keyword in the text and analyze its local meaning in relation to a number of words immediately preceding and following it (Luhn, 1960). In this study, KWIC was performed using the R package 'Quanteda' for managing and analyzing text (Benoit et al., 2018). An example of KWIC analysis is related to the Italian word forte, which means 'fort' but is also used as the adjective 'strong'. For this reason, the word forte was not included in the dictionary and was replaced by the word Giorgio to detect the architectural building Forte di San Giorgio. In this way, KWIC allows a better selection of keywords to be included in the dictionary. Table 1 shows an example of dictionary related to the 'Culture, history, and art' dimension. 
Table 1. Example of 'Culture, history, and art' dimension dictionary.

\begin{tabular}{|c|c|c|c|}
\hline Dimension & Attributes & $\begin{array}{l}\text { Attributes identified with } \\
\text { content analysis }\end{array}$ & Dictionary keywords \\
\hline \multirow[t]{3}{*}{$\begin{array}{l}\text { Culture, } \\
\text { history, and } \\
\text { art }\end{array}$} & $\begin{array}{l}\text { Museums, } \\
\text { historical } \\
\text { buildings, } \\
\text { monuments }\end{array}$ & $\begin{array}{l}\text { Penal colony } \\
\text { The Castle of San Giorgio } \\
\text { Churches (Assunta, San Nicola, } \\
\text { etc.) } \\
\text { Towers (Zenobito, Dattero, } \\
\text { Teglia, etc.) }\end{array}$ & $\begin{array}{l}\text { prison; penal }^{\star} \text {; colon }{ }^{\star} ; \\
\text { church }^{\star} \text {; giorgio; san; } \\
\text { tower }^{\star} \text {; castle; far } \\
\text { pirat }^{\star} \text {; saracen } \\
\text { architecture; } \\
\text { monument } \\
\text { history }{ }^{\star} \text {; historical; } \\
\text { building }\end{array}$ \\
\hline & $\begin{array}{l}\text { Festival and } \\
\text { concerts }\end{array}$ & $\begin{array}{l}\text { Squid Festival } \\
\text { Tuscany Walking Festival } \\
\text { Capraia Music Festival } \\
\text { Capraia Rock Trail }\end{array}$ & $\begin{array}{l}\text { squid }^{\star} \text {; feast }{ }^{\star} \text {; festival; } \\
\text { art; music; rock trail; } \\
\text { walking festival, music } \\
\text { festival, capraia rock trail }\end{array}$ \\
\hline & Gastronomy & $\begin{array}{l}\text { Aleatico wine - PGI } \\
\text { Vermentino wine - PGI } \\
\text { Goat's milk cheeses - PAT } \\
\text { Honey - PAT } \\
\text { Myrtle and myrtle liqueur } \\
\text { Fish } \\
\text { Wild fennel and fennel liqueur }\end{array}$ & $\begin{array}{l}\text { food }^{\star} ; \text { aleatico; chees } \\
\text { honey; fish } \\
\text { h; laborator } \\
\text { shop } \\
\text { s; } \text { tast }^{\star} ; \text { mirto; } \\
\text { vermentino; wine } \\
\text { fennel } \\
\text { aperitif } \text { liqueur }^{\star} \text {; PGI, PAT }\end{array}$ \\
\hline
\end{tabular}

Notes: PAT: Prodotto agroalimentare tradizionale, an official approval for traditional Italian regional food products, similar to the Protected Geographical Status of the European Union; PGI: Protected Geographical Indications.

\section{Results}

This study analyzed 24 web pages (4,461 unique words after the pre-processing phase) related to local operators, DMOs, and institutions, and retrieved and analyzed 4,928 tourist posts from Instagram (14,907 unique words after the pre-processing phase). The results found that the analyzed characteristics of content structure differ when comparing content generated by the supply (SGC) and demand (DGC) sides. The mean number of words used by tourists $(\mu$ $=8.99)$ to communicate their experience is far less than in content published by local operators $(\mu=573.46)$. This result is not surprising, because the contemporary media landscape is characterized by the creation of short texts on social networks (Vázquez-Herrero et al., 2019).

The dictionary created to detect the destination image of Capraia was applied to SGC and DGC. The results show differences between the communication of operators and the perception of tourists (see Table 2). 
Table 2. Distribution of dimensions (\%).

\begin{tabular}{lll}
\hline Dimensions & SGC & DGC \\
\hline Atmosphere of the place & $14.96 \%$ & $48.64 \%$ \\
Culture, history, and art & $20.00 \%$ & $5.07 \%$ \\
Tourist leisure & $23.90 \%$ & $33.66 \%$ \\
General infrastructure & $6.83 \%$ & $3.84 \%$ \\
Natural resources & $34.31 \%$ & $8.79 \%$ \\
\hline
\end{tabular}

Note: The percentage of each dimension is calculated on the frequency words in each dimension divided by the total number of frequency words collected in all dimensions of our dictionary, separately for SGC and DGC.

The atmosphere of the place dimension includes emotional and intellectual attitudes related to the experience in the destination. The persuasive effect of emotional appeal is analyzed considering specific words such as 'relax', 'love', and 'beautiful'. The dimension of culture, history, and art comprises the heritage of the island and considers festivals, museums, historical buildings, monuments, handicrafts, and gastronomy. Meanwhile, the leisure dimension was included because it is one of the main motivations that encourages people to travel; in Italy, more than $70 \%$ of holidays spent in tourist accommodation establishments are related to leisure motivation (Istituto Nazionale di Statistica, 2020). Tourists want new experiences to escape from daily routine, and Capraia offers several kinds of activities and experiences, such as trekking, boat excursions, or diving, which are included in the leisure dimension. References to public and private physical structures, such harbours or roads, are included in the specific dimension of general infrastructure. The last dimension, natural resources, includes natural aspects which characterize the island, such as bays, Mediterranean scrub, water, and flowers.

In order to provide a comprehensive picture, the results are represented through heatmaps (see Figure 2), with color intensity representing the ratio between the number of keywords found for each dimension and the total number of words. Color brightness demonstrates an imbalance in communication between tourists and local operators. While the supply side mainly promotes the dimensions related to tourist leisure (23.9\%) and natural resources $(34.3 \%)$, tourists communicate mostly about aspects of local atmosphere (48.6\%), including emotional and intellectual attitudes, both in relation to the island heritage as well as their own experience in the destination. These results reflect the aim of the social network as a tool developed to share experiences and emotions. 


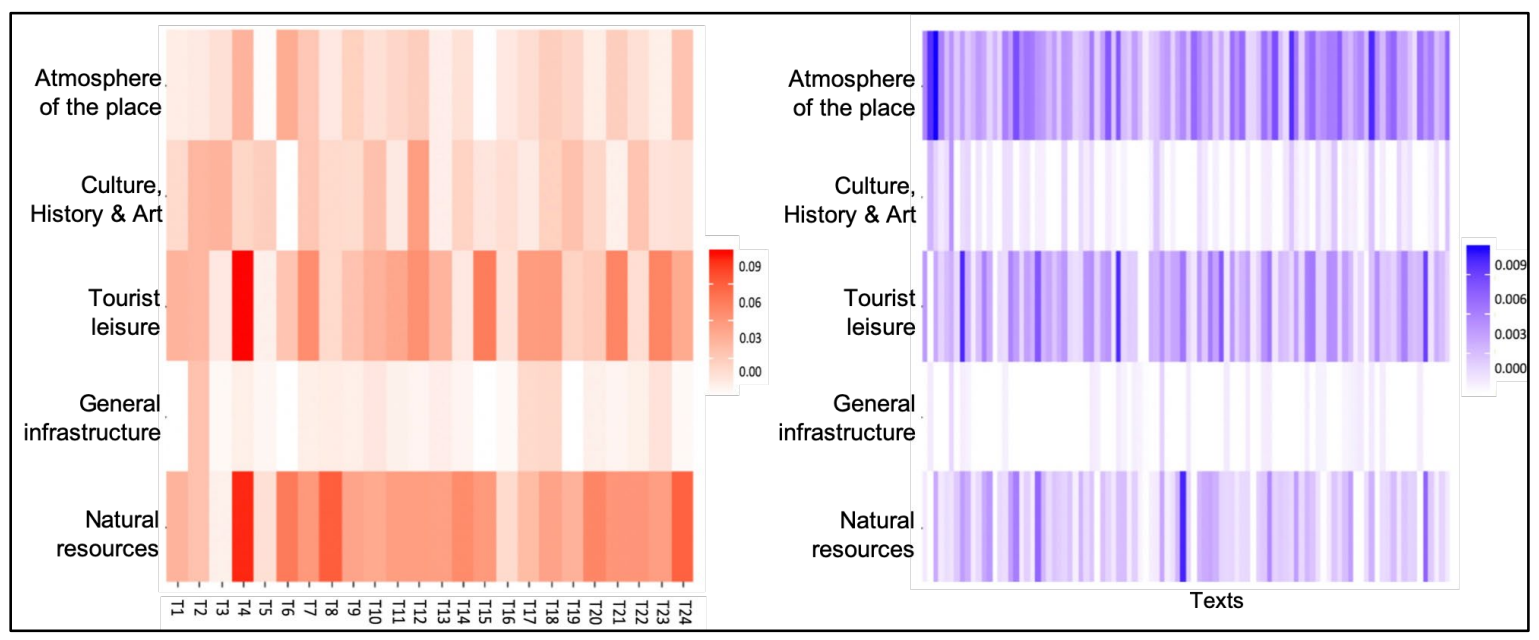

Figure 2. Heatmaps representing SGC (left) and DGC (right) findings. Color intensity depicts the ratio between the number of keywords in each dimension and the total number of words in the websites/posts. Website texts/Instagram posts are represented on the $\mathrm{X}$ axis, while the $\mathrm{Y}$ axis shows the dimensions analyzed.

Table 3 demonstrates the five most-used keywords adopted for each dimension by the supply and demand sides. It is on the atmosphere of the place dimension that a different use of words and topics emerges between tourists and local operators. Understanding the potential effects of emotionally appealing and experiential messages communicated by tourists could represent an important element for local operators in designing attractive communication content. The main content posted by tourists included the words 'view', 'sunset', and 'blue'. While for many tourists the end of each day on holiday represents a magical moment in which the sunset can be enjoyed in total relaxation, the word 'sunset' was not found in the supplygenerated content. Another element of interest is related to the frequency of English-language keywords, such as 'love' and 'beautiful', adopted by tourists to underline feelings and personal experiences. This probably also depends on whether the keyword is usually enclosed as hashtag in the Instagram post and whether users share their sentiments through the most popular Instagram hashtags (Manikonda et al., 2014). For the other dimensions, we can observe similar content being communicated, but with a different frequency; this is particularly relevant for the tourist leisure dimension, in which tourists place greater priority upon the communication based on sea and coves. 
Table 3. Top 5 keywords across dimensions by supply (SGC) and demand (DGC).

\begin{tabular}{|c|c|c|c|c|}
\hline \multirow{2}{*}{ Dimensions } & \multicolumn{2}{|l|}{ SGC } & \multicolumn{2}{|l|}{ DGC } \\
\hline & Word & $\%$ & Word & $\%$ \\
\hline \multirow{5}{*}{$\begin{array}{l}\text { Atmosphere of the } \\
\text { place }\end{array}$} & Spring & 13.0 & View & 12.0 \\
\hline & Paradise & 8.7 & Sunset & 10.9 \\
\hline & Blue & 7.6 & Blue & 9.2 \\
\hline & View & 6.5 & Love & 7.9 \\
\hline & Silence & 6.5 & Beautiful & 5.9 \\
\hline \multirow{5}{*}{$\begin{array}{l}\text { Culture, history, and } \\
\text { art }\end{array}$} & Penal colony & 11.4 & St. Giorgio & 19.5 \\
\hline & Castle & 10.6 & Prison & 17.1 \\
\hline & St. Giorgio & 9.8 & Castle & 14.6 \\
\hline & Pirates & 9.0 & Penal Colony & 12.2 \\
\hline & Myrtle & 7.3 & Lighthouse & 9.8 \\
\hline \multirow{5}{*}{ Tourist leisure } & Coves & 15.6 & Sea & 44.5 \\
\hline & Sea & 10.2 & Coves & 26.5 \\
\hline & Trekking & 6.8 & Aperitif & 7.0 \\
\hline & Fishing & 6.8 & Snorkeling & 4.4 \\
\hline & Snorkeling & 4.1 & Boat/sailboat & 3.7 \\
\hline \multirow{5}{*}{$\begin{array}{l}\text { General } \\
\text { infrastructure }\end{array}$} & Harbor & 47.6 & Harbor & 83.9 \\
\hline & Ferryboat & 16.7 & Ferryboat & 12.9 \\
\hline & Taxi Boat & 14.3 & Toremar & 3.2 \\
\hline & Rental & 9.5 & & \\
\hline & Toremar & 7.1 & & \\
\hline \multirow{5}{*}{ Natural resources } & Archipelago & 10.9 & Bay/Tip & 25.4 \\
\hline & Park & 9.0 & Water & 11.3 \\
\hline & Bay/tip & 8.1 & Archipelago & 9.9 \\
\hline & Mediterranean & 6.7 & Helichrysum & 9.9 \\
\hline & $\begin{array}{l}\text { scrub } \\
\text { Rocks }\end{array}$ & 5.7 & Nature & 8.5 \\
\hline
\end{tabular}

Overall, SGC on Capraia tries to catch the attention of different types of tourists, focusing on specific aspects such as the opportunity to discover the island through hiking, playing sports, enjoying Mediterranean vegetation and the blue sea, and tasting myrtle liqueur produced on the island. In order to match the communication adopted by the supply side and the demand side, a dictionary based on Capraia's main points of interest was created (see Figure 3). 


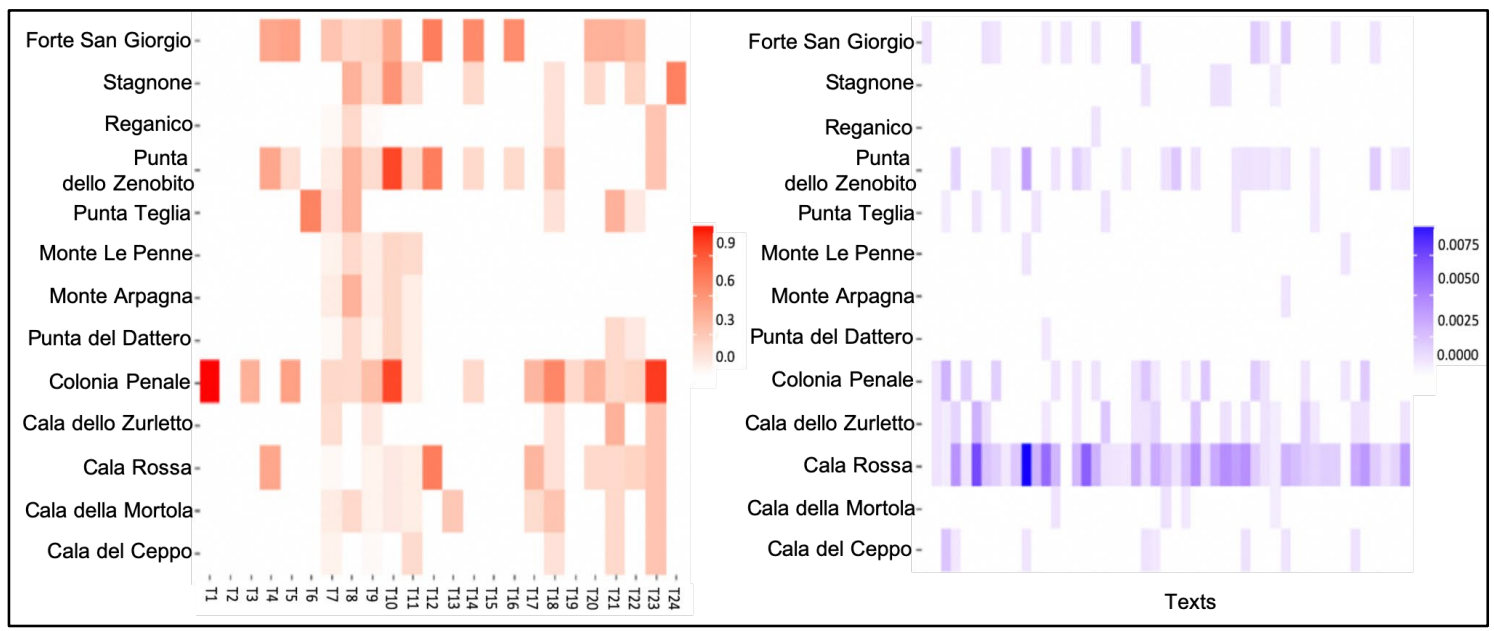

Figure 3. Location heatmaps communicated by the supply side (left) and demand side (right). Color intensity depicts the ratio between the number of keywords in each dimension and the total number of words in the websites/posts. Website texts/Instagram posts are represented on the $\mathrm{X}$ axis, while the $\mathrm{Y}$ axis shows the dimensions analyzed.

These findings present a different framework. The supply side, on the whole, uses a wider range of points of interest, including locations on the hills, thereby presenting Capraia as suitable for hiking and visiting historical buildings, while tourists focus their attention on what they consider to be the main destination attractions, mainly sea and swimming. The left-hand side of Figure 3 shows that local operator communication mainly focuses on locations related to cultural and historical aspects of the island, particularly the former penal colony (Colonia Penale); this is not surprising, given its relevance in Capraia's social evolution and history. The site is composed of several building complexes (called branch-sections) located in the north of the island, without any outstanding building corresponding to the established iconography of prisons. Today, some of these buildings are abandoned and can only be seen from the outside. The penal colony occupied about 30\% of Capraia's surface and is now able to be crossed by hiking paths that connect it to some of the island's points of interest. The communication of local operators also focuses on locations related to cultural and historical aspects of the island, including the penal colony as well as San Giorgio fort.

Despite its prominence as a point of interest in SGC, the Colonia Penale receives far less attention in DGC. The same can be said for the hills and the lake (Stagnone) which, although proposed in SGC, are seldom mentioned in DGC. Intriguingly, local agricultural productions are totally neglected in both SGC and DGC, as are naturalistic hotspots related to vegetation, such as the rare populations of rose-bay and palms, or wild animals such as mouflon. Instead, tourists mainly communicate on one of the most visited coves of the island, Cala Rossa (see Figure 3, right), which is the old crater of a former volcano and is easily recognizable by its lava-lit red rocks which make a nice contrast to the blue sea.

\section{Conclusion}

Theoretical and practical implications

It is widely recognized that destination image plays a considerable role in destination selection (Lee T. H., 2009), and that social media platforms are nowadays considered as a reliable source 
of information, even more than traditional communication channels (Foux, 2006). It has been also demonstrated how tourism information in social media and its quality can influence the construction of destination image (Kim S. E. et al., 2017). On the other hand, the point of view of the hegemonic (typically urban) culture expressing demand - which in this case is more evidently reflected in DGC - must also be considered within SGC so as to present a destination as attractive to potential customers (Figueiredo \& Raschi, 2011).

Discrepancies between the destination image proposed in SGC and the one emerging from DGC have also been described in other research. In a study about Taiwan (Michaelidou et al., 2013), significant differences were evidenced between online photographs generated by visitors and those created by government agencies and marketers, with visitors underlining participation and interaction with local culture and local cuisine, while marketers stressed nature and contemporary images of the country. Lim et al. (2012), in a study about Las Vegas, found that although most of the keywords were common between SGC and DGC, their frequency was different, and the number of dominant themes was higher in SGC than in DGC. A comparison between images posted by the official Peru tourism website and those posted by tourists on the platform Flickr (Stepchenkova \& Zhan, 2013) evidenced a different geographical distribution of images, as tourists mainly posted images from the most famous tourist sites, while images on the official website were evenly distributed among all regions, in an attempt to promote the whole country. Intriguingly, despite the prominence of environmental attractions of Peru, plants were underrepresented both on the official site and in the Flickr images (Stepchenkova \& Zhan, 2013).

Similar discrepancies were evidenced also in our research. Additionally, in our study, even Mediterranean wild animals that are typical of local fauna were not mentioned. Capraia, on the basis of DGC, appears as limited to "sun and sea" vacation, with very minor interest in local environment. The common tourists' desire to experience the authentic everyday life of local people (Markwick, 2001), which could be reflected in local historical remnants related to Capraia's recent history, also seems neglected, probably in consequence of the elevated "cultural proximity" (Kastenholz, 2010) of visitors, ruling out any exoticism-related interests. On the other hand, the SGC seems to stress the elements that built the local identity, such as the penal colony, or the presence of a lake or the Mediterranean forests on the hills.

Destination image is a key concept for understanding how a destination is placed in the tourism market; measuring destination image is a means to detect which attributes and dimensions are objects of tourists' valuation. Monitoring online conversations has become a powerful tool to understand how participants in tourism markets talk about a destination. Tourism operators can acquire a better knowledge about tourists' beliefs and expectations (Baloglu \& McCleary, 1999; Gartner, 1994, 1996), and develop more targeted marketing strategies with the aim of increasing consumer engagement. At the same time, more information about the market can better inform and drive entrepreneurs' decisions. From a policy maker perspective, capturing and collecting destination details through online content and understanding the differences between stakeholders can provide supplementary information useful in designing promotion campaigns and supporting small local operators of the island.

The findings of this study have several practical implications. Firstly, some of the dimensions analyzed are under-represented in the online content generated by the supply side. This imbalance could be perceived by tourists as synonymous of poor attention to the destination. For this reason, a first step that policy makers could take would be to conduct a 
review of the communication strategy to ensure that it is balanced on all dimensions, as this is recognized as a factor influencing destination image. A constant monitoring of communication could support stakeholders in destination image management, contributing in maximizing the efforts made to promote the destination.

Moreover, the comparison between SGC and DGC showed that tourists and local operators only partially communicate the same information about Capraia. Tourists place greater priority on communication based on emotional appeal and personal experience on the island; the atmosphere of the place is the main dimension communicated by tourists on Instagram. Meanwhile, the supply side offers poor communication in terms of emphasizing emotions. Policy makers, local authorities, and enterprises should consider a tourism communication strategy plan which leverages the emotional appeal of the content. Zhang and colleagues (2018, p. 1093) highlighted that "technology is critical for facilitating the experience value cocreation process in tourism." For this reason, it could be interesting to set up the formation of destination image on real experiences, encouraging tourists to promote their emotions during and after travel. It is wise to design destination marketing campaigns which involve tourists and integrate the voices of tourists and online content generated from different stakeholders (DMOs, citizens, enterprises, etc.).

This practical implication is reflected in previous studies analyzing strategies successfully adopted by DMOs to promote destinations. In some cases, DMOs involved 'influencers' to talk about the destination. Ong and Ito (2019) investigated Singaporeans' travel consumption to Hokkaido, Japan following a campaign promoted by Hokkaido Tourism Organization which engaged one of Singapore's top influencers to talk about the destination. Results showed a $20 \%$ increase in the tourism number from Singapore. Another best practice identified by Oliveira and Panyik (2015) related to a campaign adopted by Visit Sweden on Twitter, which selected a different Swede to communicate their thoughts through the social platform every week. The campaign was developed with the aim of presenting Sweden to the world and reaching 69,200 followers (Oliveira \& Panyik, 2015). Both of these campaigns have had strong positive responses, which could be a result of the gap between supply and demand communications being filled.

\section{Limitations and future research}

While this research suffers from some limitations, they can be considered as opportunities for possible future development of the study. Firstly, the constant updating of websites by local operators and the continuous publication on social networks by tourists make data collected quickly obsolete. Despite this, our study considered a long-time span, allowing us to analyze content generated by tourists who had visited Capraia at some point over a period of four years. Secondly, while the current analysis is based solely on Instagram posts, future studies could investigate different social networks (such as Facebook, Twitter, or Pinterest) and also review sites, such as TripAdvisor. Comparing results of communication on different social platforms could support decision-makers in implementing different tourism strategies. Thirdly, our analysis is limited to online content written in the Italian language; future studies should aim to explore contents in other languages. This could allow a deep investigation of strategies adopted in different countries with the aim of understanding which kind of dimensions the tourism market prioritizes, which would in turn enable comparison of results from other studies on islands with the aim of defining a model to analyze the destination image of islands. 


\section{Funding}

This work was supported by the Tuscany Region (Italy) under PROSVINT project.

\section{References}

Alcañiz, E. B., García, I. S., \& Blas, S. S. (2009). The functional-psychological continuum in the cognitive image of a destination: A confirmatory analysis. Tourism Management, 30(5), 715-723. https://doi.org/10.1016/j.tourman.2008.10.020

Baloglu, S., \& McCleary, K. W. (1999). A model of destination image formation. Annals of Tourism Research, 26(4), 868-897. https://doi.org/10.1016/S0160-7383(99)00030-4

Beerli, A., \& Martin, J. D. (2004). Factors influencing destination image. Annals of Tourism Research, 31(3), 657-681. https://doi.org/10.1016/j.annals.2004.01.010

Benoit, K., Watanabe, K., Wang, H., Nulty, P., Obeng, A., Müller, S., \& Matsuo, A. (2018). quanteda: An R package for the quantitative analysis of textual data. Journal of Open Source Software, 3(30), 774. https://doi.org/10.21105/joss.00774

Blain, C., Levy, S. E., \& Ritchie, J. B. (2005). Destination branding: Insights and practices from destination management organizations. Journal of Travel Research, 43(4), 328-338. https://doi.org/10.1177/0047287505274646

Blei, D. M., Ng, A. Y., \& Jordan, M. I. (2003). Latent Dirichlet allocation. Journal of Machine Learning Research, 3, 993-1022.

Camilleri, A., Colombini, I., \& Chelazzi, L. (2012). Evolution and management of landscapes on Mediterranean minor islands: Case studies from the Tuscan Archipelago (Italy) and Comino (Malta). In E. Conrad \& L. Cassar (Eds.), Landscape approaches for ecosystem management in Mediterranean Islands (pp. 169-204). Institute of Earth Systems, University of Malta.

Choi, S., Lehto, X. Y., \& Morrison, A. M. (2007). Destination image representation on the web: Content analysis of Macau travel related websites. Tourism Management, 28(1), 118-129. https://doi.org/10.1016/j.tourman.2006.03.002

Crompton, J. L. (1979). An assessment of the image of Mexico as a vacation destination and the influence of geographical location upon that image. Journal of Travel Research, 17(4), 18-23. https://doi.org/10.1177/004728757901700404

Dichter, E. (1985). What's in an image. Journal of Consumer Marketing, 2(1), 75-81. http://dx.doi.org/10.1108/eb038824

Fedele, S., De Ascaniis, S., \& Cantoni, L. (2011). Destination marketing and users' appraisal: Looking for the reasons why tourists like a destination. In R. Law, M. Fuchs, \& F. Ricci (Eds.), Information and Communication Technologies in Tourism 2011: Proceedings of the International Conference in Innsbruck, Austria, January 26-28, 2011 (pp. 151-163). Springer.

Figueiredo, E., \& Raschi, A. (2011). «Un'immensa campagna avvolta dal verde» Reinventing rural areas in Italy through tourism promotional images. European Countryside, 3(1), 1-20. https://www.researchgate.net/publication/227640142

Foggi, B., Viciani, D., Baldini, R. M., Carta, A., \& Guidi, T. (2015). Conservation assessment of the endemic plants of the Tuscan Archipelago, Italy. Oryx, 49(1), 118-126. https://doi.org/10.1017/S0030605313000288 
Foux, G. (2006). Consumer-generated media: Get your customers involved. Brand Strategy, 8(202), 38-39.

Gartner, W. C. (1996). Tourism development: Principles, processes, and policies. John Wiley and Son. https://doi.org/10.1002/jtr.288

Gartner, W. C. (1994). Image formation process. Journal of Travel \& Tourism Marketing, 2(23), 191-216. https://doi.org/10.1300/J073v02n02 12

Girardin, F., Calabrese, F., Dal Fiore, F., Ratti, C., \& Blat, J. (2008). Digital footprinting: Uncovering tourists with user-generated content. IEEE Pervasive Computing, 7(4), 3643. https://doi.org/10.1109/MPRV.2008.71

Grydehøj, A. (2008). Branding from above: Generic cultural branding in Shetland and other islands. Island

Studies

Journal, 3(2),

175-198.

https://islandstudies.ca/sites/default/files/ISJ-3-2-2008-Grydehoj.pdf

Guo, L., Vargo, C. J., Pan, Z., Ding, W., \& Ishwar, P. (2016). Big social data analytics in journalism and mass communication: Comparing dictionary-based text analysis and unsupervised topic modeling. Journalism \& Mass Communication Quarterly, 93(2), 332359. https://doi.org/10.1177/1077699016639231

Hunt, J. D. (1975). Image as a factor in tourism development. Journal of Travel Research, 13(3), 1-7. https://doi.org/10.1177/004728757501300301

Istituto Nazionale di Statistica. (2020). Turismo. In Annuario Statistico Italiano 2019 (pp. 620648). Retrieved February 2021 from https://www.istat.it/it/files//2020/12/C19.pdf

Kastenholz, E. (2010). 'Cultural proximity' as a determinant of destination image. Journal of Vacation Marketing, 16(4), 313-322. https://doi.org/10.1177/1356766710380883

Kavaratzis, M., \& Hatch, M. J. (2013). The dynamics of place brands: An identity-based approach to place branding theory. Marketing Theory, 13(1), 69-86. https://doi.org/10.1177\%2F1470593112467268

Kim, J., \& Fesenmaier, D. R. (2017). Sharing tourism experiences: The post trip experience. Journal of Travel Research, 56(1), 28-40. https://doi.org/10.1177/0047287515620491

Kim, S., \& Lehto, X. Y. (2013). Projected and perceived destination brand personalities: The case of South Korea. Journal of Travel Research, 52(1), 117-130. https://doi.org/10.1177\%2F0047287512457259

Kim, S. E., Lee, K. Y., Shin, S. I., \& Yang, S. B. (2017). Effects of tourism information quality in social media on destination image formation: The case of Sina Weibo. Information $\& \quad$ Management, 54(6), $\quad$ 687-702. https://doi.org/10.1016/j.im.2017.02.009

Kim, S. S., McKercher, B., \& Lee, H. (2009). Tracking tourism destination image perception. Annals of Tourism Research, 36(4), 715-718. https://doi.org/10.1016/j.annals.2009.04.007

Kislali, H., Kavaratzis, M., \& Saren, M. (2016). Rethinking destination image formation. International Journal of Culture, Tourism and Hospitality Research, 10(1), 7080. https://doi.org/10.1108/IJCTHR-05-2015-0050

Költringer, C., \& Dickinger, A. (2015). Analyzing destination branding and image from online sources: A web content mining approach. Journal of Business Research, 68(9), 1836-1843. https://doi.org/10.1016/j.jbusres.2015.01.011 
Kong, W. H., du Cros, H., \& Ong, C. E. (2015). Tourism destination image development: A lesson from Macau. International Journal of Tourism Cities, 1(4), 1-17. https://doi.org/10.1108/IJTC-08-2014-0016

Lee, S. W., \& Xue, K. (2020). A model of destination loyalty: Integrating destination image and sustainable tourism. Asia Pacific Journal of Tourism Research, 25(4), 39-408. https://doi.org/10.1080/10941665.2020.1713185

Lee, T. H. (2009). A structural model to examine how destination image, attitude, and motivation affect the future behavior of tourists. Leisure Sciences, 31(3), 215-236. https://doi.org/10.1080/01490400902837787

Li, J. J., Ali, F., \& Kim, W. G. (2015). Reexamination of the role of destination image in tourism: An updated literature review. E-review of Tourism Research, 12(3/4), 191-209.

Lim, Y., Chung, Y., \& Weaver, P. A. (2012). The impact of social media on destination branding: Consumer-generated videos versus destination marketer-generated videos. Journal of Vacation Marketing, 18(3), 197-206. https://doi.org/10.1177/1356766712449366

Luhn, H. P. (1960). Key word-in-context index for technical literature (kwic index). American Documentation, 11(4), 288-295. https://doi.org/10.1002/asi.5090110403

Mak, A. H. (2017). Online destination image: Comparing national tourism organisation's and tourists' perspectives. Tourism Management, 60, 280-297. https://doi.org/10.1016/j.tourman.2016.12.012

Manikonda, L., Hu, Y., \& Kambhampati, S. (2014). Analyzing user activities, demographics, social network structure and user-generated content on Instagram. arXiv. https://arxiv.org/pdf/1410.8099.pdf

Markwick, M. (2001). Postcards from Malta: Image, consumption, context. Annals of Tourism Research, 28(2), 417-438. https://doi.org/10.1016/S0160-7383(00)00049-9

Michaelidou, N., Siamagka, N. T., Moraes, C., \& Micevski, M. (2013). Do marketers use visual representations of destinations that tourists value? Comparing visitors' image of a destination with marketer-controlled images online. Journal of Travel Research, 52(6), 789-804. https://doi.org/10.1177/0047287513481272

Nechita, F., Demeter, R., Briciu, V. A., Varelas, S., \& Kavoura, A. (2019). Projected destination images versus visitor-generated visual content in Brasov, Transylvania. In A. Kavoura, E. Kefallonitis, \& A. Giovani (Eds.), Strategic innovative marketing and tourism (pp. 613-622). Springer. https://doi.org/10.1007/978-3-030-12453-3 70

Oliveira, E., \& Panyik, E. (2015). Content, context and co-creation: Digital challenges in destination branding with references to Portugal as a tourist destination. Journal of Vacation Marketing, 21(1), 53-74. http://doi.org/10.1177/1356766714544235

Ong, Y. X., \& Ito, N. (2019). “I want to go there too!” Evaluating social media influencer marketing effectiveness: A case study of Hokkaido's DMO. In J. Pesonen \& J. Neidhardt (Eds.), Information and communication technologies in tourism 2019 (pp. 132144). Springer. https://doi.org/10.1007/978-3-030-05940-8

Qu, H., Kim, L. H., \& Im, H. H. (2011). A model of destination branding: Integrating the concepts of the branding and destination image. Tourism Management, 32(3), 465-476. https://doi.org/10.1016/j.tourman.2010.03.014 
Ramseook-Munhurrun, P., \& Naidoo, P. (2015). Examining the structural relationships of destination image, perceived value, tourist satisfaction and loyalty: Case of Mauritius. Procedia-Social and Behavioral Sciences, 175, 252-259. https://doi.org/10.1016/j.sbspro.2015.01.1198

Regione Toscana. (2018). Movimento Turisti Nelle Strutture Ricettive e Struttura Dell'offerta. Retrieved October 2020 from https://www.regione.toscana.it/-/movimento-turistinelle-strutture-ricettive-e-struttura-dell-offerta-dati-2018

Ruiz-Real, J. L., Uribe-Toril, J., \& Gázquez-Abad, J. C. (2020). Destination branding: Opportunities and new challenges. Journal of Destination Marketing \& Management, 17, 100453. https://doi.org/10.1016/j.jdmm.2020.100453

Santo, A. P. (2021). A new magma type in the continental collision zone. The case of Capraia Island (Tuscany, Italy). Geosciences, 11(2), 104. https://doi.org/10.3390/geosciences11020104

Schmunk, S., Höpken, W., Fuchs, M., \& Lexhagen, M. (2013). Sentiment analysis: Extracting decision-relevant knowledge from UGC. In Z. Xiang \& I. Tussyadiah (Eds.), Information and communication technologies in tourism 2014 (pp. 253-265). Springer. https://doi.org/10.1007/978-3-319-03973-2 19

Statista. (2021). Number of monthly active Instagram users from January 2013 to June 2018. Retrieved February 2021 from https://www.statista.com/statistics/253577/numberof-monthly-active-instagram-users/

Stepchenkova, S., \& Zhan, F. (2013). Visual destination images of Peru: Comparative content analysis of DMO and user-generated photography. Tourism Management, 36, 590-601. https://doi.org/10.1016/j.tourman.2012.08.006

Stepchenkova, S., Kirilenko, A. P., \& Morrison, A. M. (2009). Facilitating content analysis in tourism research. Journal of Travel Research, 47(4), 454-469. https://doi.org/10.1177/0047287508326509

Taboada, M., Brooke, J., Tofiloski, M., Voll, K., \& Stede, M. (2011). Lexicon-based methods for sentiment analysis. Computational Linguistics, 37(2), 267-307. https://doi.org/10.1162/COLI a 00049

Tasci, A. D., \& Gartner, W. C. (2007). Destination image and its functional relationships. Journal of Travel Research, 45(4), 413-425. https://doi.org/10.1177\%2F0047287507299569

Vázquez-Herrero, J., Direito-Rebollal, S., \& López-García, X. (2019). Ephemeral journalism: News distribution through Instagram stories. Social Media + Society, 5(4). https://doi.org/10.1177/2056305119888657

Weber, R. P. (1990). Basic content analysis (2nd ed.). Sage. https://dx.doi.org/10.4135/9781412983488

Welbers, K., Van Atteveldt, W., \& Benoit, K. (2017). Text analysis in R. Communication Methods and Measures, 11(4), 245-265. https://doi.org/10.1080/19312458.2017.1387238

Xiang, Z., \& Gretzel, U. (2010). Role of social media in online travel information search. Tourism Management, 31(2), https://doi.org/10.1016/j.tourman.2009.02.016 
Xiang, Z., Gretzel, U., \& Fesenmaier, D. R. (2009). Semantic representation of tourism on the Internet. Journal of Travel Research, 47(4), 440-453. https://doi.org/10.1177/0047287508326650

Zhang, H., Gordon, S., Buhalis, D., \& Ding, X. (2018). Experience value cocreation on destination online platforms. Journal of Travel Research, 57(8), 1093-1107. https://doi.org/10.1177\%2F0047287517733557

Zhang, K., Chen, Y., \& Li, C. (2019). Discovering the tourists' behaviors and perceptions in a tourism destination by analyzing photos' visual content with a computer deep learning model: The case of Beijing. Tourism Management, 75, 595-608. https://doi.org/10.1016/j.tourman.2019.07.002 